\title{
Virgin Olive Oil of Ouslati and Chemlali Tunisian Cultivars: Quality Parameters and Aroma Biosynthesis during the Oil Extraction Process
}

\author{
Faouzi Sakouhi ${ }^{*}$, Chaima Saadi ${ }^{1}$, Wahid Herchi ${ }^{1}$, Mohamed Alibi ${ }^{2}$, Cioni Pier Luigi ${ }^{3}$ and Sadok \\ Boukhchina $^{1}$
}

${ }^{1}$ Laboratoire Biochemistry of Lipids, Department of Biology, Faculty of Sciences of Tunis, 2092 El Manar II. Tunisie

${ }^{2}$ Office State Lands, arboricultural sector and arboriculture, 106 Avenue Alain SAVARY, Cité El Khadra, Tunis

${ }^{3}$ Dipartimento of Bioorganic Chemistry and biopharmacy, Universita di Pisa, Via Bonanno 33, 561266, Pisa, Italy

*Corresponding author: Faouzi Sakouhi, Laboratory Biochemistry of Lipids, Department of Biology, Faculty of Sciences of Tunis, 2092 El Manar II. Tunisie, Tel: +216 22142 610; Fax: +216 71885480; E-mail: faouzi.sakouhi@fst.rnu.tn

\begin{abstract}
The accumulation of aroma compounds starts at the moment of cell disruption during the crushing of the olive fruits (pulps and stones) through the lipoxygenase (LOX) pathway. In order to understand the part of pulp and stone in the biogenesis of virgin olive oil (VOO) aroma, the constitutive parts of olive fruits of two Tunisia cultivars (Ouslati and Chemlali) were separately analysed. According to the obtained results, significant differences on the LOX volatiles composition were observed between olive pulps and stones $(\mathrm{P}<0.05)$. These differences can be attributed to the difference in the distribution and the activity of LOX enzymes in pulp and stone. Our results showed that the LOX volatile compounds have mainly their bio-accumulation in pulp (about $90 \%$ for Ouslati and Chemlali cvs) than in stone (10\%). (E)-2-hexenal was the dominant aldehydic compound in both crushed pulp and stone. However, 3-pentanone, (E)-2-pentenal, pentanal, 1-penten-3-ol and 1-pentanol were present in lower amount in olive pulps than in stones. Moreover, quality parameter results (free acidity, peroxide value and fatty acids composition) obtained from VOO of Ouslati and Chemlali cultivars were within the limits established by the International Olive Oil Council.
\end{abstract}

Keywords: Olive oil; Quality; Aroma; Pulp; Stone; Biosynthesis
Received Date: May 10, 2016

Accepted Date: May 24, 2016

Published Date: May 27, 2016

Citation: Sakouhi, F., et. al. Virgin Olive Oil of Ouslati and Chemlali Tunisian Cultivars: Quality Parameters and Aroma Biosynthesis during the Oil Extraction Process. (2016) Int J Food Nutr Sci 3(1): 285-291.

DOI: $10.15436 / 2377-0619.16 .915$

\section{Introduction}

Olea europaea L. products such as olive oil and table olive have been characterized by their special flavor and aroma. These products represent the fundamental food in the Mediterranean Countries. In 2014, the olive oil production of Tunisia amounted to 285000 tons, which makes it the most important virgin olive oil producer in the Mediterranean ${ }^{[1]}$. The olive products are highly appreciated for their nutritional properties, as well as for their delicate and unique aroma ${ }^{[2]}$. Flavour and aroma of olive oils are generated by a number of bio-molecules that are present in extremely low concentrations ${ }^{[3,4]}$. The aroma consists of a complex mixture of volatiles. Some of these components are found in the intact tissue of the fruit; others are formed during the oil extraction process via the lipoxygenase (LOX) pathway ${ }^{[5-7]}$. The main precursors of these volatiles are fatty acids containing a (Z, Z)-1, 4-pentadiene structure such as linoleic (LA) and linolenic (LnA) acids ${ }^{[8]}$ (Figure 1). The first step of LOX pathway is the conversion of LA and LnA into their corresponding 13-hydroperoxide derivatives that are subsequently cleaved by the hydroperoxide lyase enzyme (HPL) 
to produce $\mathrm{C} 6$ volatile aldehydes ${ }^{[9]}$. C6 aldehydes can then undergo successive reactions catalysed by alcohol dehydrogenases ${ }^{[10]}$ $(\mathrm{ADH})$ and alcohol acyltransferases ${ }^{[11]}$ (AAT) to form, respectively, C6 volatile alcohols and their corresponding esters. However, C5 volatile compounds are generated through an additional branch of the LOX pathway to produce C5 alcohols and their corresponding aldehydes. This additional LOX branch was demonstrated in soybean seeds ${ }^{[12]}$ and in tomato plants ${ }^{[13]}$.

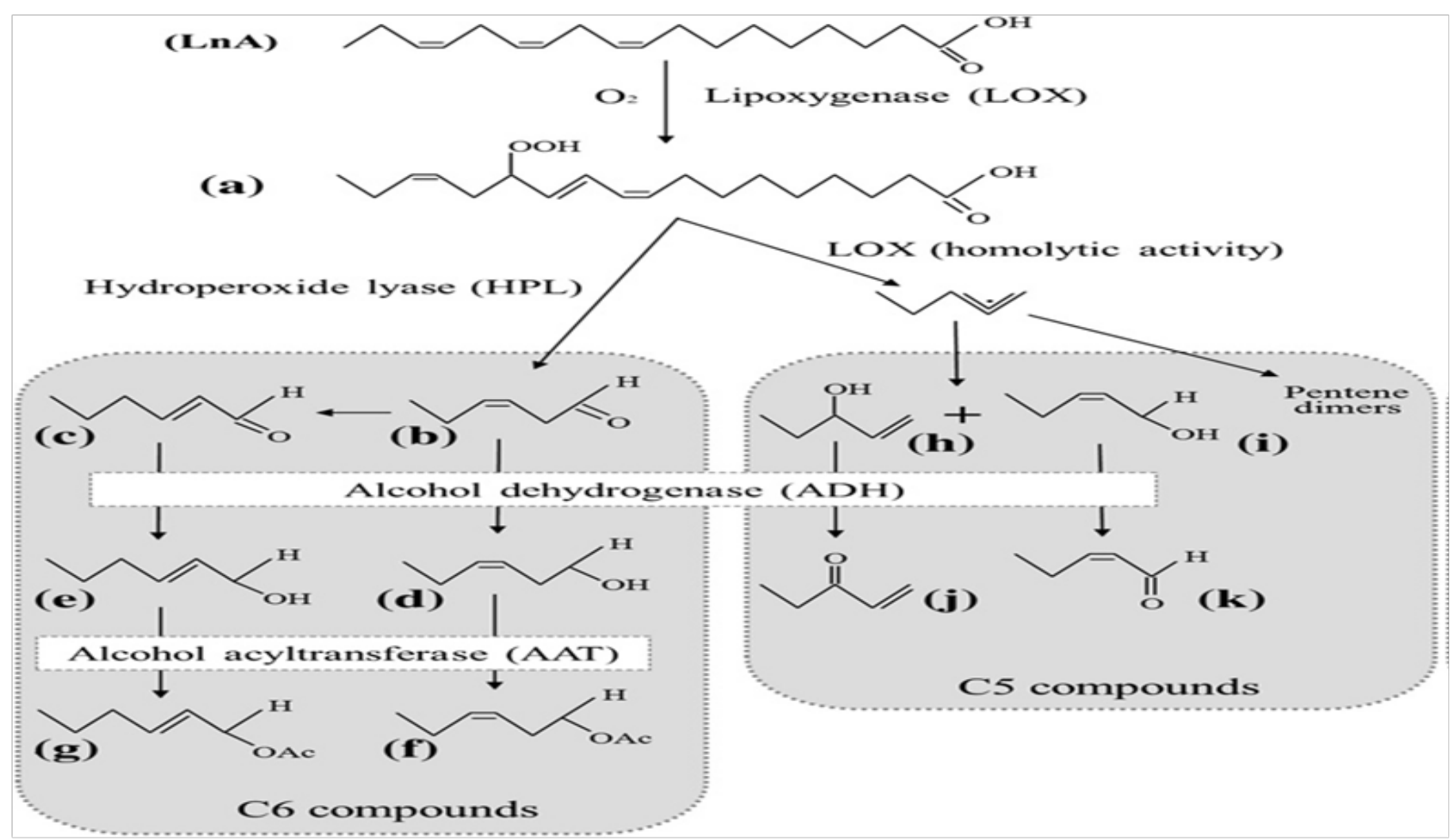

Figure 1: Scheme of LOX pathway on linolenic acid (LnA) for the synthesis of main volatile compounds in virgin olive oil. (a), 13-hydroperoxide-LnA (13-HPOT); (b), (Z)-hex-3-enal; (c), (E)-hex-2-enal; (d), (Z)-hex-3-enol; (e), (E)-hex-2-enol; (f), (Z)-hex-3-en-1-yl acetate; (g), (E)-hex2-en-1-yl acetate; (h), pent-1-en-3-ol; (i), (Z)-pent-2-en-1-ol; (j), pent-1-en-3-one; (k), (Z)-pent-2-enal.

In olive fruits, the accumulation of volatile compounds responsible for virgin olive oil (VOO) aroma occurs during the milling step of olive oil processing. The characterization of olive oil volatiles is considered one of the keys for VOO quality control ${ }^{[14]}$. In olive oils, the formation of aroma compounds starts at the moment of cell disruption during the crushing of the olive fruits (pulps and stones) and continuous during the extraction process ${ }^{[15]}$. In literature, and the best of our knowledge little information have been published concerning the aroma distribution between pulp and stone in olives for oil extraction. Thus, the aim of the present work is to study the aroma distribution of the constrictive parts: pulps and stones to determine their role in the biogenesis of VOO aroma of the Tunisian Ouslati and Chemlali cultivars.

\section{Material and Methods}

\section{Reagents and standards}

(E)-2-pentenal, (E)-hex-2-en-1-yl acetate, (E)-hex-2-enal, (E)-hex-2-enol, (E)-hex-3-enol, (E)-pent-2-en-1-ol, (Z)-3-hexen-1-ol acetate, (Z)-hex-2-enol, (Z)-hex-3-enol, (Z)-pent-2-en-1-ol, 1-pentanol, 2-methyl-butanal, 3-methyl-butanol, acetic acid, ethyl acetate, ethyl hexanoate, hexan-1-ol, hexanal, methyl acetate, methyl hexanoate, nonanal, ocimene, pent-1-en-3-ol, pentan-2-one, and pentanal were purchased from Sigma Aldrich (St. Louis, MO, USA). (E, E)- $\alpha$-Farnesene is from TCI America. All standards were of high-purity grade. Standard solutions and their diluted preparations were stored in a dark flask at $-20{ }^{\circ} \mathrm{C}$.

\section{Olive samples}

The olive varieties of Ouslati and Chemlali were grown on the Agronomy farm of Bousalem situated in north-east of Tunisia (Latitude: 34" 36' N; Longitude: 17" 58' E; Altitude: $127 \mathrm{~m}$ above sea level). This site is characterized by a typically Mediterranean climate with a mean annual rainfall of $450 \mathrm{~mm}$ concentrated mainly from November to December. The olive fruits were collected from each cultivar at the same stage of ripeness, and the maturity index was rated as 4.2 in all olive samples. The maturity index was determined on the basis of the evaluation of the olive skin and pulp colors ${ }^{[16]}$. Varieties were selected on the basis of their higher oil production and their greatest adaptation for Tunisian climatic conditions. 


\section{Extraction of olive oils}

The extraction process of virgin olive oil was achieved with a hammer crusher. In brief, olives from each cultivar were washed and crashed, and the paste was mixed at $25^{\circ} \mathrm{C}$ for $30 \mathrm{mn}$. After centrifugation, the oil was filtered, and then transferred into dark glass bottles, and stored at $-4{ }^{\circ} \mathrm{C}$.

\section{Quality parameters determinations}

Free acidity was determined according to the analytical methods described in the European Union Commission ${ }^{[17]}$. In fact, free acidity given as percentage of oleic acid, was determined by titration of a solution of the oil dissolved in ethanol/ether with $0.1 \mathrm{M}$ potassium hydroxide ethanol solution. UV spectrophotometric indices (K232 and K270) were carried out according to the analytical methods described by the International Olive Oil Counci[18]. Samples were analyzed in quartz cuvettes, using DU 730 spectrophotometer, Beckman Coulter (Brea, California).

Peroxide value was determined following the method described by European Union Commission ${ }^{[17]}$. In brief, $1 \mathrm{~g}$ of oil was added to $25 \mathrm{ml}$ of acetic acid/chloroform (3:2, v/v) and $1 \mathrm{ml}$ of saturated KI solution. Next, $75 \mathrm{ml}$ of deionized water and $0.5 \mathrm{ml}$ of starch solution $[10 \mathrm{~g} / 1]$ were added to the mixture. The obtained solution was titrated with $0.01 \mathrm{~N}$ sodium thiosulfate. Data obtained were expressed as $\mathrm{mEq}$ of $\mathrm{O}_{2}$ per $\mathrm{kg}$ of oil.

Fatty acids (FA) composition was achieved using the method reported by the International Olive Oil Council ${ }^{[19]}$. The fatty acids methyl esters were prepared by vigorous hand-shaking of a solution of oil in hexane $(0.2 \mathrm{~g}$ in $3 \mathrm{ml})$ with $0.4 \mathrm{ml}$ of methanolic potassium hydroxide $2 \mathrm{~N}$, and then $1 \mu \mathrm{l}$ of the solution was injected into GC with a FID detector. A fused silica column (50 m length x $0.25 \mathrm{~mm}$ i.d.), coated with SGL-1000 phase (0.25 $\mu \mathrm{m}$ thickness; Sugar labor, Spain), was used. The carrier gas was helium, at a flow through the column of $1 \mathrm{ml} / \mathrm{min}$. The temperatures of the injector and detector were set at $250{ }^{\circ} \mathrm{C}$ and the oven temperature at $210{ }^{\circ} \mathrm{C}$

\section{Extraction of volatiles}

To evaluate the aroma compounds production from the constitutive parts of the olive, pulp and stone were crushed separately. A porcelain mortar was used for crushing stones. Two grams of the crushed material (pulp and stone) was placed into a $10 \mathrm{~mL}$ vial with the internal standard (2-octanol). Finally, the vial was maintained at $25^{\circ} \mathrm{C}$ for 15 min to develop the LOX pathway activity, and then, $2 \mathrm{~mL}$ of saturated solution of $\mathrm{CaCl}_{2}$ were added as an enzymatic inhibitor, following the protocol previously described by Servili et al ${ }^{[20]}$.

After the later preparation, Supelco SPME devices coated with polydimethylsiloxane (PDMS, $100 \mu \mathrm{m})$ were used to headspace the sample of pulp or stone inserted into a $5 \mathrm{ml}$ glass vial, and then, allowed to equilibrate for $30 \mathrm{~min}$. After the equilibration time, the fiber, preconditioned according to the manufacturer's recommendations, was exposed to the headspace for 50 min at room temperature. Once sampling was finished, the fiber was withdrawn into the needle and transferred to the injection port of the GC and GC-MS system.

\section{GC and GC-MS analyses of volatiles}

The GC analyses of volatiles were accomplished with an HP-5890 series II instrument equipped with HP-Wax and HP-5 capillary columns $\left(30 \mathrm{~m} \times 0.25 \mathrm{~mm}, 0.25 \mu \mathrm{m}\right.$ film thikness), working with the following temperature program: $60{ }^{\circ} \mathrm{C}$ for $10 \mathrm{mn}$, ramp of $5^{\circ} \mathrm{C} / \mathrm{min}$ to $220^{\circ} \mathrm{C}$; injector and detector temperatures, $250^{\circ} \mathrm{C}$; carrier gas, nitrogen $(2 \mathrm{ml} / \mathrm{min})$; detector, dual FID; injection, $0.5 \mu$ l.

The GC-EIMS analyses were performed with a Varian CP-33800 gas-chromatograph equipped with a DB-5 capillary column $(30 \mathrm{~m}$ x $0.25 \mathrm{~mm}$; coating thickness $=0.25 \mu \mathrm{m})$ and a Varian Saturn 2000 ion trap mass detector. Analytical conditions: injector and transfer line temperatures, 220 and $240^{\circ} \mathrm{C}$, respectively; oven temperature programmed from 60 to $240^{\circ} \mathrm{C}$ at $3^{\circ} \mathrm{C} / \mathrm{min}$; carrier gas, helium at $1 \mathrm{ml} / \mathrm{min}$; injection, $0.2 \mu \mathrm{l}$ (10\% hexane solution).

The identification of volatile compounds was achieved by comparing their MS spectra, MS fragmentation patterns and retention time with those of the pure standards analyzed under the same conditions; and by means of their linear retention indices (LRI) relative to the series of n-hydrocarbons. The unknown peaks were tentatively identified by comparing their MS spectra with reference spectra of compounds of different libraries (resemblance percentage above 80\%). Search was mainly made in the following GC MS libraries: NIST 98 Mass Spectral Library, and Wiley Mass Spectral Library. Moreover, the molecular mass of the identified compounds was confirmed by GC-CIMS, using $\mathrm{MeOH}$ as $\mathrm{CI}$ ionizing gas.

Quantitative data of the identified volatile compounds were obtained using their integrated peak area and interpolating the value on the corresponding calibration curve according to the validated method for the analysis of virgin olive oil volatiles reported by Servili et al. ${ }^{[20]}$.using 2-octanol as internal standard which is not present in the volatile fraction of olive oil.

\section{Statistical analysis}

In all analyses, three replicates were used and the results were expressed as mean value \pm standard derivation. Data were statistically analyzed by one-way analysis of variance (ANOVA), by using Tukey's test at a significance level of 0.05 . 


\section{Results and Discussion}

\section{Quality parameters}

The quality parameter results of the studied olive oils were shown in table 1 . The amounts of these parameters obtained from Ouslati and Chemlali olive oils were relevant to the norms established by the International Olive Oil Counci ${ }^{[19]}$. The free fatty acid (FFA) amount (expressed in \% of C18:1 content) was 0.4 and $0.3 \%$, respectively, for Ouslati and Chemlali olive oils. The FFA values of our samples were lower than $0.8 \%$ (Table 1), which indicated that oils obtained from the studied olive fruits were classed as extra-virgin ${ }^{[17]}$. The acidity index measures the alteration of triacylglycerols in oil. Dabbou et al ${ }^{[21]}$ reported that the acidity index of olive oils was closely related to the process of harvesting, extracting methods and storage conditions.

Table 1: Quality parameters and fatty acids compositiona (expressed in \% of total fatty acids) of Ouslati and Chemlali olive oils.

\begin{tabular}{|c|c|c|c|c|}
\hline \multicolumn{2}{|c|}{ Parameter } & Ouslati & Chemlali & COI reference ${ }^{b}$ \\
\hline \multirow{4}{*}{ 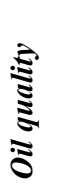 } & Acidity (\%) & $0.4 \pm 0.1$ & $0.3 \pm 0.1$ & $\leq 0.8$ \\
\hline & Peroxide value (meq/kg) & $3.2 \pm 0.8$ & $4.8 \pm 1.0$ & $\leq 20$ \\
\hline & K232 & $1.2 \pm 0.2$ & $1.8 \pm 0.3$ & $\leq 2.5$ \\
\hline & K270 & $0.1 \pm 0.1$ & $0.2 \pm 0.1$ & $\leq 0.2$ \\
\hline \multirow{8}{*}{ 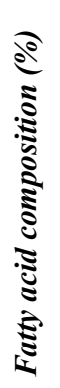 } & Palmitic (P, C16:0) & $12.0 \pm 1.6$ & $15.2 \pm 2.0$ & $7.5-20.0$ \\
\hline & Palmitoleic (Po, C16:1) & $0.3 \pm 0.1$ & $0.2 \pm 0.1$ & $0.3-3.5$ \\
\hline & Stearic (S, C18:0) & $2.6 \pm .8$ & $3.0 \pm 1.0$ & $0.5-5.0$ \\
\hline & Oleic (O, C18:1) & $78.0 \pm 6.3$ & $59.9 \pm 4.6$ & $55-83$ \\
\hline & Linoleic (L, C18:2) & $5.5 \pm 1.3$ & $20.0 \pm 2.5$ & $3.5-25.0$ \\
\hline & Linoleinic (Ln, C18:3) & $0.6 \pm 0.6$ & $0.8 \pm 0.7$ & $\leq 1$ \\
\hline & Arachidic (A, C20:0) & $0.6 \pm 0.3$ & $0.5 \pm 0.2$ & $\leq 0.6$ \\
\hline & Eicosenoic (E, C20:1) & $0.2 \pm 0.1$ & $0.3 \pm 0.1$ & $\leq 0.4$ \\
\hline
\end{tabular}

aEach value is the main \pm SD of three determinations.

${ }^{b}$ Limit values established by the International Olive Oil Council.

Regarding the peroxide value (PV), results showed that Ouslati PV (3.2 meq/kg) was lower than that of Chemlali (4.8 meq/ $\mathrm{kg}$ ) olive oils. This result can be explained by the lower amount of linoleic acid (C18:2) in Ouslati oil (Table1). In fact, oils with high degree of polyunsatured fatty acids are most susceptible to autoxidation ${ }^{[22]}$.

The analysis of fatty acids content showed that our samples contained much higher unsaturated fatty acids (UFA) and lower saturated fatty acids (SFA). In fact, UFA composition has gained much attention owing to its beneficial implications on human health ${ }^{[23]}$. According to current dietary guidance for healthy nutrition, UFA/SFA ratio above 1.5 is associated with good health ${ }^{[24]}$. The results obtained from the quality parameters analysis of our samples were in agreement with those from other olive oil cultivars, such as, Chetoui from Tunisia ${ }^{[25]}$, Picholine from Morocco ${ }^{[26]}$ and Picual from Spain ${ }^{[27]}$.

\section{Volatiles}

In order to understand the role of olive pulp and stone in the accumulation of VOO aroma, the constitutive parts of olive fruits were separately analysed. The volatile compounds identified in both crushed pulps and stones from Ouslati and Chemlali cvs are given in table 2. Results showed a significant difference $(\mathrm{P}<0.05)$ in the volatiles composition between pulps and stones for the two cultivars. This difference can be attributed to the distribution and the activity of enzymes that catalyze the biosynthesis of volatiles such as hydroperoxide lyase (HPL), alcohol dehydrogenase (ADH) and alcohol acyltransferase (AAT). Results from table 1 showed that the amount of total LOX-compounds (expressed in $\mu \mathrm{g} / \mathrm{kg}$ of oil) was much higher in crushed pulp (ranging from 4877.81 to $5451.12 \mu \mathrm{g} / \mathrm{kg}$ oil, respectively for Ouslati and Chemlali) than in crushed stone (ranging from 513.79 from $597.36 \mu \mathrm{g} /$ $\mathrm{kg}$ oil, respectively for Ouslati and Chemlali olive oils). These results showed that more than $90 \%$ of LOX-compounds responsible for the VOO aroma of Ouslati and Chemlali were generated in the pulp of the olive fruits, and that the contribution of LOX pathway activity was much higher in the pulp than in stone of olives. In the same context, Servili et al ${ }^{[20]}$ reported that the contribution of LOX activity was more than $80 \%$ in olive stoning of Coratina and Frantoio cultivars. Moreover, Rodríguez et al ${ }^{[15]}$ mentioned that $\mathrm{C} 6$ and C5 volatiles, from some Spanish olive fruits, have mainly accumulated in olive pulps (80-90\%).

Table 2 showed that the aroma of both crushed pulps and stones was formed by aldehydes, alcohols, esters, ketones and terpenes. The characterization of each individual volatiles class in the constitutive olive parts has great importance to establish the proportion of each one in the formation of $\mathrm{VOO}$ aroma. Regarding the aldehydic composition, the amount of total aldehyde components was 2964.12 and $3446.88 \mu \mathrm{g} / \mathrm{kg}$ oil, respectively in Ouslati and Chemlali crushed pulps, while in crushed stone the concentration of aldehydic volatiles ranged from 338.97 to $407.80 \mu \mathrm{g} / \mathrm{kg}$ oil, repectively (Table 2). Moreover, aldehydes were the dominant volatile classes in both crushed pulps and stones from the two cultivars. These results can indicate that the activity of hydroperoxide lyase enzyme that catalyzes the cleavage of 13-hydroperoxide (precursor of the biosynthesis of aldehydes) is much higher in olive pulps than stones ${ }^{[28]}$. The quantitative characterization of aldhyde class showed that (E)-2-hexenal was the dominant aldehydic compound 
which counted between 2620.97 and $3077.72 \mu \mathrm{g} / \mathrm{kg}$ oil for Ouslati and Chemlali pulps, respectively. Hexanal was present at lower amount in Ouslati (319.62 $\mu \mathrm{g} / \mathrm{kg}$ oil) and Chemlali (333.47 $\mu \mathrm{g} / \mathrm{kg}$ oil) crushed pulps (Table 2). This corresponding figure was also observed in crashed stones. Thus, in both crashed pulps and stones the amount of (E)-2-hexenal which has LnA as synthesis precursor was relatively higher than hexanal (LA). This result can be explained by the fact that LnA is the preferred substrate for LOX enzyme than LA ${ }^{[29]}$. The higher LOX activity for LnA supports the biogenesis of more of C6 and C5 LnA volatiles, which are the dominant components of VOO from Ouslati and Chemlali cultivars (about 90\% of LOX-compounds) (Table 2).

Table 2: Volatiles content* (expressed in $\mu \mathrm{g} / \mathrm{kg}$ of fresh olive weight) in both crushed pulps and stones of Ouslati and Chemlali olive cultivars.

\begin{tabular}{|c|c|c|c|c|c|}
\hline \multirow{2}{*}{ Compound } & \multirow{2}{*}{$\mathbf{L R I}^{* *}$} & \multicolumn{2}{|c|}{ Ouslati } & \multicolumn{2}{|c|}{ Chemlali } \\
\hline & & Pulp & Stone & Pulp & Stone \\
\hline Pentanal (LA) & 796 & n.d. & $48.57 \pm 2.35^{\mathrm{a}}$ & n.d. & $50.81 \pm 2.61^{\mathrm{a}}$ \\
\hline Hexanal (LA) & 802 & $319.62 \pm 16.58^{\mathrm{a}}$ & $89.92 b \pm 5.89^{b}$ & $333.47 \pm 17.19^{\mathrm{a}}$ & $100.50 \pm 5.74^{b}$ \\
\hline (E)-2-pentenal (LnA) & 810 & $23.53 \pm 1.53^{\mathrm{b}}$ & $7.57 \pm 0.66^{c}$ & $35.70 \pm 2.37^{\mathrm{a}}$ & $6.19 \pm 0.53^{c}$ \\
\hline (E)-2-hexenal (LnA) & 848 & $2620.97 \pm 56.86^{\mathrm{b}}$ & $192.91 \pm 9.40^{\mathrm{d}}$ & $3077.72 \pm 31.93^{\mathrm{a}}$ & $250.30 \pm 11.00^{c}$ \\
\hline$\Sigma$ Aldehydes & & 2964.12 & $338 . .97$ & 3446.88 & 407.80 \\
\hline 1-Penten-3-ol (LnA) & 838 & $10.22 \pm 0.88^{\mathrm{b}}$ & n.d. & $12.52 \pm 1.06^{\mathrm{a}}$ & n.d. \\
\hline (E)-2-penten-1-ol (LnA) & 842 & $23.89 \pm 1.64^{\mathrm{b}}$ & n.d. & $29.41 \pm 1.89^{\mathrm{a}}$ & n.d. \\
\hline (E)-3-hexen-1-ol (LnA) & 846 & $3.40 \pm 0.85^{\mathrm{b}}$ & n.d. & $5.61 \pm 0.38^{\mathrm{a}}$ & n.d. \\
\hline (Z)-3-hexen-1-ol (LnA) & 849 & $740.02 \pm 46.09^{\mathrm{a}}$ & $50.63 \pm 2.51^{b}$ & $745.82 \pm 7.71^{\mathrm{a}}$ & $56.09 \pm 2.92^{b}$ \\
\hline 1-Pentanol (LA) & 856 & $51.88 \pm 2.69^{\mathrm{b}}$ & $7.19 \pm 0.55^{\mathrm{c}}$ & $57.06 \pm 3.73^{\mathrm{a}}$ & $6.55 \pm 0.54^{\mathrm{c}}$ \\
\hline (E)-2-hexen-1-ol (LnA) & 861 & $174.33 \pm 9.23^{b}$ & $12.41 \pm 1.41^{\mathrm{c}}$ & $207.29 \pm 13.04^{\mathrm{a}}$ & $15.32 \pm 1.34^{\mathrm{c}}$ \\
\hline 1-Hexanol (LA) & 869 & $320.61 \pm 16.76^{\mathrm{a}}$ & $36.45 \pm 2.15^{\mathrm{b}}$ & $331.02 \pm 16.45^{\mathrm{a}}$ & $38.53 \pm 2.00^{\mathrm{b}}$ \\
\hline$\Sigma$ Alcohols & & 1314.12 & 106.67 & 1388.73 & 116.48 \\
\hline Hexyl acetate (LA) & 1014 & $166.14 \pm 8.28^{\mathrm{a}}$ & $23.86 \pm 1.97^{\mathrm{c}}$ & $110.18 \pm 7.10^{\mathrm{b}}$ & $20.56 \pm 1.53^{c}$ \\
\hline (Z)-3-hexenyl acetate $(\operatorname{Ln} A)$ & 1016 & $325.84 \pm 16.27^{\mathrm{b}}$ & $30.66 \pm 1.85^{\mathrm{c}}$ & $471.20 \pm 21.66^{\mathrm{a}}$ & $36.26 \pm 2.14^{\mathrm{c}}$ \\
\hline$\Sigma$ Esters & & 491.98 & 54.52 & 581.37 & 56.82 \\
\hline 3-Pentanone (LA) & 661 & $30.44 \pm 1.97^{\mathrm{b}}$ & $13.63 \pm 0.93^{\mathrm{c}}$ & $34.13 \pm 2.17^{\mathrm{a}}$ & $16.26 \pm 1.27^{\mathrm{c}}$ \\
\hline$\Sigma$ Ketones & & 30.44 & 13.63 & 34.13 & 16.26 \\
\hline$\alpha$-Pinene & 942 & $26.18 \pm 2.90^{\mathrm{b}}$ & n.d. & $30.92 \pm 2.22^{\mathrm{a}}$ & n.d. \\
\hline p-Cymene & 1030 & $11.54 \pm 0.97^{\mathrm{b}}$ & $2.82 \pm 0.35^{\mathrm{c}}$ & $13.48 \pm 1.27^{\mathrm{a}}$ & $4.09 \pm 0.27^{\mathrm{c}}$ \\
\hline Limonene & 1035 & $10.91 \pm 1.16^{\mathrm{b}}$ & n.d. & $14.38 \pm 1.23^{\mathrm{a}}$ & n.d. \\
\hline$(E, E)-\alpha-F a r n e s e n e$ & 1503 & $18.31 \pm 1.30^{\mathrm{b}}$ & $4.73 \pm 0.41^{\mathrm{c}}$ & $20.51 \pm 2.04^{\mathrm{a}}$ & $6.11 \pm 0.49^{c}$ \\
\hline$\Sigma$ Non-LOX compounds & & 66.94 & 7.55 & 79.28 & 10.20 \\
\hline$\Sigma(\mathrm{C} 5+\mathrm{C} 6)(\mathrm{LA})$ & & 888.69 & 219.62 & 865.85 & 233.21 \\
\hline$\Sigma(\mathrm{C} 5+\mathrm{C} 6)(\operatorname{Ln} \mathrm{A})$ & & 3922.19 & 294.18 & 4585.26 & 364.15 \\
\hline LOX compounds/olive part & & 4810.87 & 513.79 & 5451.12 & 597.36 \\
\hline Total volatiles/olive part & & 4877.81 & 521.34 & 5530.40 & 607.56 \\
\hline Total olive fruit volatiles & & 5399.15 & 6137.96 & & \\
\hline
\end{tabular}

a-c Values (Mean \pm S.E., $\mathrm{n}=9$ ) with different letters in the same row are significantly different $(\mathrm{P} \leq 0.05)$.

*Each value is the main \pm SD of three determinations.

**LRI: linear retention index calculated on DB-WAX capillary column.

The alcohol volatile fraction was formed via the reversible reduction of aliphatic aldehydes which is catalysed by the alcohol dehydrogenase (ADH) enzyme. The quantitative characterization of alcohol fraction showed that the amount of total alcohols was 1314.12 and $1388.73 \mu \mathrm{g} / \mathrm{kg}$ oil in crushed pulps, respectively for Ouslati and Chemlali cultivars, respectively. However, just small quantity of these components was detected in the stones for both cultivars. (Z)-3-Hexen-1-ol, 1-hexanol and (E)-2-hexen-1-ol were the main alcohol components detected in both crushed pulps and stones. These results were expected since hexanal (LA) and E-(2)-hexen-1-al (dominant aldehydes) were the biosynthetic precursors, respectively for 1-hexanol and (E)-2-hexen-1-ol via alcohol dehydrogenase (ADH) enzyme. (Z)-3-Hexen-1-ol, dominant alcohol component, was of 740.02 and $745.82 \mu \mathrm{g} / \mathrm{kg}$ oil in crushed pulps, respectively for Ouslati and Chemlali cultivars. (E)-3-hexen-1-ol, penten-3-ol and 1-pentanol were present in crushed pulps but they were not detected in crushed stones for both Ouslati and Chemlali olives (Table 2). The lack in C5 alcohols (1-pentanol and penten-3-ol) in crushed stones could be explained by the fact that C5 aldehydes were not transformed into their respective C5 alcohols, although olive stones contained a considerable quantity of $\mathrm{ADH}$ as reported by Luaces et al[30]. The later results can indicate that 
$\mathrm{ADH}$ is more specific for $\mathrm{C} 6$ aldehydes than $\mathrm{C} 5$ volatile aldehydes. Moreover, the obtained results from crushed pulps showed that about $72 \%$ of LOX alcohol compounds were synthesized via linolenic acid (LnA). However, $60 \%$ of alcohols from crushed stones were generated via Linoleic acid (LA). In addition to aldehydes and alcohols components, volatile fraction of both crushed olive pulps and stones contained hexyl acetate and (Z)-3-hexenyl acetate as esters. The later components were generated from (E)-2-hexen-1-ol and (Z)-3-hexen-1-ol by the action of alcohol acetyl transferase (AAT) enzyme[30]. Similar to the aldehydes and alcohols, ester compounds were much higher accumulated in olive pulps than stones for Ouslati and Chemlali cultivars (Table2).

3-Pentanone represents the unique ketone component which is identified in both crushed pulps and stones for the two cultivars. Ketone fraction (3-Pentanone) was present in much lower level than the other volatile chemical classes in all cultivars. This result is expected since 3-pentanone and the others C5 volatile compounds ((E)-2-pentenal (LnA), pentanal (LA), 1-penten-3-ol and 1-pentanol) were generated through an additional branch of the LOX pathway that explained the lower amount of these volatile components in both Ouslati and Chemlali cultivars. Gardner et al ${ }^{[12]}$ demonstrated that in soybean seeds, the additional branch of LOX pathway involve the production of 13-alcoxyl radical which is subsequently transformed into 1,3-pentene allylic radical to form C5 alcohols. Regarding the characterization of the terpenic fraction, results showed that these components were found in lower content (Table 2). Only two terpenes (p-Cymene and (E,E)- $\alpha$-farnesene) were found in both crashed pulps and stones. However, $\alpha$-pinene and limonene were identified just in crushed pulp. As the other volatile classes, terpenes were more generated in pulps than stones in Ouslati and Chemlali olive cultivars.

\section{Conclusions}

The analysis of crushed pulp and stone separately gives important information about the contribution of olive constitutive parts on the biosynthesis of VOO aroma. The main volatile compounds responsible for the VOO aroma had their accumulation in the pulp of fruits. According to these results, the contribution of LOX pathway activity was much higher in the pulp (more than $80 \%$ ) than in stone. The main volatiles were generated via linolenic acid (LnA) than linoleic one (LA). Significant difference in the quantitative characterization of volatiles was observed between pulp and stone, independently of cultivars considered. 3-Pentanone, (E)-2-pentenal, pentanal, 1-penten-3-ol and 1-pentanol were present in lower amount in olive pulp because they are generated through the additional branch of the LOX pathway.

\section{Acknowledgements}

This work has been done as a part of a national Research Project. We thank the Ministry of scientific Research, Technology and Competence Development of Tunisia for financially supporting this investigation.

\section{References}

1. International Olive Oil Cousil, $6^{\text {th }}$ meeting of the IOC statistics working group (2015) Madrid, September.

2. Luna,G. Morales,M.T., Aparicio,R. Characterization of 39 varietal virgin olive oils by their volatile compositions. (2006) Food Chem 98(2):243252.

3. Giovacchino, L.D., Costantini, N., Serraiocco, A., et al. Natural antioxidants and volatile compounds of virgin olive oils obtained by two or three-phases centrifugal decamters. (2001) Eur J Lipid Sci Technol 103(5):279-285.

4. Kiritsakis, A.K., Christie,W.W. Analysis of edible oils, In J. Harwood and R. Aparicio, (Eds), Handbook of olive oil : analysis and properties. (2000) Gaithersburg, MD: Aspen Publishers pp: 129-158.

5. Salas,J.J., Sánchez,C., Gaarcía-González,D.L., et al. Impact of the suppression of lipoxygenase and hydroperoxide on the quality of the green odour in green leaves. (2005) J Agric Food Chem 53(5): 1648-1655.

6. Sanchez, J., Harwood, J.L. Biosynthesis of Triacylglycerols and volatiles in olives. (2002) Eur J Lipid Sci Technol 104(9-10): 564-573.

7. Morales, M.T., Tsimidou, M. The role of volatile compounds and polyphenols in olive oil sensory quality, In J. Harwood \& R. Aparicio, (Eds), Handbook of olive oil: analysis and properties. 2000Gaithersburg, MD: Aspen Publishers, pp 393-458.

8. Sánchez, O.A., Pérez, A.G., Sanz, C. Synthesis of aroma compounds of virgin olive oil: Significance of the cleavage of polyunsaturated fatty acid hydroperoxides during the oil extraction process. (2013) Food Res Int 54(2): 1972-1978.

9. Salas, J.J., Sánchez, J. Hydroperoxide lyase from olive (Olea europaea) fruits. (1999) Plant Science 143(1): 19-26.

10. Salas, J.J., Sánchez, J. Alcohol dehydrogenases from olive (Olea europaea) fruit. (1998) Phytochemistry 48(1): 35-40.

11. Salas, J.J. Characterization of alcohol acyltransferase from olive fruit. (2004) J Agric Food Chem 52(10): 3155-3158.

12. Gardner, H.W., Grove, M.J., Salch, Y.P. Enzymic pathway to ethyl vinyl ketone and 2-pentenal in soybean preparations. (1996) J Agric Food Chem 44(3): 882-886.

13. Vancanneyt, G., Sanz, C., Farmaki, T., et al. Hydroperoxide lyase depletion in transgenic potato plants leads to an increase in aphid performance. (2001) Proc Natl Acad Sci U S A 98(14): 8139-8144.

14. Angerosa, F., Servili, M., Selvaggini, R., et al. Volatile compounds in virgin olive oil: Occurrence and their relationship with quality. (2004) J Chromatogr A 1054(1-2), 17-31.

15. Rodríguez, P.R., Barreiro, G.C., Grande, C.B., et al. Aroma biogenesis and distribution between olive pulps and seeds with identification of aroma trends among cultivars. (2013) Food Chem 141(1): 637-643.

16. Boskou,D. Olive oil: Chemistry and technology. (1996)Champaign, IL: AOCS Press, pp. 85-127.

17. European Union Commission, Commission Regulation No. 61/2011 of 24 January 2011 amending Regulation No. 2568/91 on the characteristics of olive oil and olive residue oil and on the relevant methods of analysis. (2011) Official Journal of the European Communities 23: 1-14. 18. International Olive Council. Method of analysis spectrophotomètric investigation in the ultraviolet. (2010). COI/T.20/Doc. No 19/Rev. 3. 
19. International Olive Council. Determination of the content of waxes fatty acid methyl esters and fatty acid ethyl esters by capillary gas chromatography. (2009) IOOC/T.20/DOC. No 28.

20. Servili, M., Taticchi, A., Esposto, S., et al. Effect of olive stoning on the volatile and phenolic composition of virgin olive oil. (2007) J Agric Food Chem 55(17): 7028-7035.

21. Dabbou, S., Sifi, S., Rjiba, I., et al. Effect of pedoclimatic conditions on the chemical composition of the Sigoise olive cultivar. (2010) Chem Biodivers 7(4): 898-908.

22. Halvorsen, B.L., Blomhoff, R. Determination of lipid oxidation products in vegetable oils and marine omega-3 supplements. (2011) Food Nutr Res 55.

23. Visioli, F., Galli, C. Biological properties of olive oil phytochemicals. (2002) Crit Rev Food Sci Nutr 42(3): $209-221$.

24. Ribarova, F., Zanev, R., Shishkov, S., et al. $\alpha$-Tocopherol, fatty acids and their correlations in Bulgarian foodstuffs. (2003) J Food compos Anal 16(6): 659-667.

25. Laroussi, M.S., Vanloot, P., Molinet, J., et al. Authentication of Tunisian virgin olive oils by chemometric analysis of fatty acid compositions and NIR spectra. Comparison with Maghrebian and French virgin olive oils. (2015) Food Chem 173: 122-132.

26. Bajoub, A., Carrasco-Pancorbo, A., Ajal, E., et al. Potential of LC-MS phenolic profiling combined with multivariate analysis as an approach for the determination of the geographical origin of north Moroccan virgin olive oils. (2014) Food Chem 166: 292-300.

27. Reboredo, R.P., González-Barreiro, C., Cancho-Grande, B., et al. Quality of extra virgin olive oils produced in an emerging olive growing area in north-western Spain. (2014) Food Chem 164: 418-426.

28. Kalua, C.M., Allen, M.S., Bedgood, D.R., et al. Olive oil volatile compounds, flavour development and quality: A critical review. (2007) Food Chem 100(1): 273-286.

29. Sánchez, J., Salas, J.J. Biogenesis of the olive oil aroma. In J. Harwood \& R. Aparicio (Eds.), Handbook of olive oil: Analysis and properties. (2000) Gaithersburg, MD, USA: Aspen publications, Inc.

30. Luaces, P., Pérez, A.G., Sanz, C. Role of olive seed in the biogenesis of virgin olive oil aroma. (2003) J Agric Food Chem 51(16): 4741-4745.

Online ISSN: 2377-0619

Journal Title: International Journal Food and Nutritional Science Journal Short Name: Int J Food Nutr Sci
Ommega Online Publishers

E-mail: foodscience@ommegaonline.org

Website: www.ommegaonline.org 